\title{
LIXIVIAÇÃO E IMOBILIZAÇÃO DE NITROGÊ NIO NUM NITOSSOLO COMO VARIÁVEIS DA FORMA DE APLICAÇÃO DA URÉIA E DA PALHA DE AVEIA(1)
}

\author{
P. R. ERNANI ${ }^{(2)}$, L. SANGOI $^{(2)} \&$ C. RAMPAZZO(3)
}

\begin{abstract}
RESUMO
A magnitude das reações do $\mathbf{N}$ no solo varia com as condições climáticas, características do solo, tipo de preparo, forma de aplicação dos fertilizantes nitrogenados e manejo da cobertura vegetal morta. 0 presentetrabalho objetivou avaliar o efeito da forma de aplicação de nitrogênio e de resíduos de aveia preta na lixiviação e imobilização do $\mathbf{N}$ num Nitossolo Vermelho. Foram realizados dois experimentos, em casa de vegetação, nos quais se combinaram formas de aplicação de $\mathbf{N}$ (sem uréia, uréia incorporada ou aplicada sobre a superfície do solo) e de palha de aveia (sem palha, palha de aveia incorporada ou aplicada na superfície do solo). No experimento de lixiviação, testou-se também o efeito do pH do solo $(5,5$ e 7,0$)$ e, no de imobilização, o efeito da época de semeadura $(0,30$ ou 60 dias após adição da palha e do $\mathrm{N}$ ). Aplicaram-se o equivalente a 4,0 $\mathrm{Mg} \mathrm{ha}^{-1}$ de matéria seca de palha, nos dois experimentos, e 200 ou $100 \mathrm{~kg} \mathrm{ha}^{-1} \mathrm{de} \mathrm{N}$, respectivamente, no experimento de lixiviação ou imobilização, cujas quantidades foram calculadas com base na área da superfície do solo das unidades experimentais. A lixiviação foi quantificada por meio da percolação de água destilada, semanalmente, durante dez semanas, em colunas de PVC. A i mobi lização foi avaliada indiretamente, por meio do rendimento de massa seca e do acúmulo de $\mathbf{N}$ na parte aérea de plantas de mi lho, semeadas nas três épocas, em diferentes unidades experimentais. A lixiviação do $\mathbf{N}$ aplicado variou de $\mathbf{2 5}$ a $70 \%$, foi maior nos tratamentos com pH 5,5 do que com pH 7,0, e naqueles com uréia incor porada do que nos com uréia sobre a superfície do solo, mas não foi influenciada pelo método de aplicação da palha de aveia. $\mathrm{O}$ milho semeado no dia da aplicação dos tratamentos apresentou os menores valores de matéria seca de parte aérea (MSPA) e de $\mathrm{N}$ acumulado, provavelmente em virtude da maior imobilização de $\mathbf{N}$ nesse período inicial. A adição de $\mathbf{N}$ aumentou esses dois atributos, mas o método de aplicação da uréia não teve influência sobre nenhum
\end{abstract}

\footnotetext{
(1) Recebido para publicação em junho de 2001 e aprovado em junho de 2002.

(2) Professor da Universidade do Estado de Santa Catarina - UDESC. Caixa Postal 281, CEP 88520-000 Lages (SC). Bolsista do CNPq. E-mail: prernani@cav.udesc.br

(3) Acadêmico de Agronomia, UDESC. Bolsista de Iniciação Científica do CNPq.
} 


\begin{abstract}
deles. A adição de pal ha sobre a superfície do solo aumentou a MSPA e o acúmulo de $\mathrm{N}$, em relação à incorporação, graças, provavelmente, à manutenção de mais umidade no solo e à menor imobilização de $\mathbf{N}$.
\end{abstract} Termos de indexação: reações do nitrogênio, formas de fertilização, pH do solo,
cobertura vegetal.

\title{
SUMMARY: EFFECT OF OAT STRAW AND UREA APPLICATION FORMS ON SOIL NITROGEN LEACHING AND IMMOBILIZATION
}

\begin{abstract}
Themagnitude of nitrogen reactions in thesoil varies according to climate conditions, soil type, soil tillage, method of nitrogen application, and plant residuemanagement. This study tried to evaluate the effect of nitrogen application methods and of black oat (Avena strigosa) residues on $\mathrm{N}$ leaching and immobilization in a Brazilian Haplumbrept by two experiments carried out in a greenhouse The treatments were combinations of thre $\mathrm{N}$ fertilization methods (without urea, urea incorporated into the soil and urea applied over the soil surface) with thre management practices of oat residues (without straw, straw incorporated into the soil and straw applied over the soil surface). As additional factors, the effect of soil pH (5.5 or 7.0) was also eval uated in thel eaching experiment and the effect of the sowing date $(0,30$, or 60 days after $\mathrm{N}$ and straw additions) in the experiment of $\mathrm{N}$ immobilization. An amount of $4.0 \mathrm{Mg} \mathrm{ha}^{-1}$ of oat straw (dry matter) was applied in both experiments, and $\mathrm{N}$ at rates of 200 or $100 \mathrm{~kg} \mathrm{ha}^{-1}$, respectively, in the leaching and immobilization trials. Straw and $\mathrm{N}$ rates were cal culated based on the surfacearea of the experimental units. Nitrogen leaching was measured weekly, for ten weeks, by percolation of distilled water through polyvinyl chloride columns. Nitrogen immobilization was estimated indirectly, by determining thedry matter and $\mathrm{N}$ accumulation in themaizeplant shoots sown at the three dates in different experimental units. The amount of leached $\mathrm{N}$ varied from 25 to $70 \%$ of the applied amount, was greater in thepH 5.5 than in the pH 7.0 treatments, and in treatments with incorporated urea than in those with urea applied over thesoil surface. Nitrogen leaching was unaffected by oat residue application, regardless of theapplication method. Dry matter of themaize shoots (DMMS) and N accumulation were lowest for plants sown on the day of treatment addition, probably due to a higher immobilization of $\mathrm{N}$ during theinitial period after the residue application. Addition of $\mathrm{N}$ increased the maize dry matter and shoot $\mathrm{N}$ uptake, but the urea application method had no influence on any of them. Residue deposition over the surface promoted higher DMMS and $\mathrm{N}$ uptake than residue incorporation, probably due to higher constant soil moisture and lower $\mathrm{N}$ immobilization.
\end{abstract}

Index terms: Nitrogen reactions, fertilization methods, cover crops, soil pH.

\section{INTRODUÇÃO}

O nitrogênio é o nutriente exigido em maior quantidade pela maioria das plantas cultivadas, apresentando efeito considerável no rendimento de grãos, principal mente quando os demais nutrientes encontram-se disponíveis em quantidades adequadas e as condições climáticas são favoráveis (Ernani et al., 1997). O aumento da eficiência de uso dos fertilizantes nitrogenados pelas plantas envolve o entendimento da dinâmica do $\mathrm{N}$ no solo em diferentes situações de manejo do solo e de plantas.
O grande número de reações do $\mathrm{N}$ no solo e a predominância da forma nítrica (Aulakh et al., 2000) fazem com que os valores de $\mathrm{N}$ mineral no solo variem amplamente, mesmo no período de poucos dias, o que dificulta a utilização de análises laboratoriais de rotina para estimar sua disponibilidade para as culturas. Sendo assim, as recomendações de fertilização nitrogenada são baseadas em experimentos regionais, cujas respostas variam com o $\mathrm{pH}$, quantidade de matéria orgânica (CFS/RS-SC, 1995), tipo de preparo (Sims et al., 1998) e características químicas do solo (Howard \& Essington, 1998), além do manejo da 
cobertura vegetal morta (Sims et al., 1998; Vaughan \& Evanylo, 1998), do tipo (Aulakh et al., 2000), da época (Basso \& Ceretta, 2000) e da forma de aplicação dos fertilizantes nitrogenados (H oward \& Essigton, 1998; Sims et al., 1998).

Nos últimos anos, houve grande expansãona área com sistema de semeadura direta, principalmente na região sul do Brasil. Nesse sistema, o solo não é revolvido e, com isso, os restos culturais não são incorporados, sendo os fertilizantes e os corretivos da aci dez aplicados sobre a superfície do solo. Essas peculiaridades afetam substancialmente algumas reações do N no solo (Howard \& Essigton, 1998; Palma et al., 1998) com magnitudes diferentes daquelas que ocorrem nos sistemas tradicionais de preparo do solo, com arações e gradagens (Amado \& Mielniczuk, 2000).

A manutenção dos restos das culturas sobre a superfície do solo aumenta a imobilização microbiológica nos estádios iniciais, subseqüentes à dessecação dos mesmos (H oward \& Essington, 1998). Por isso, normalmente é necessário adicionar maior quantidade de fertilizante nitrogenado no sistema plantio direto (SPD) do que no sistema de preparo convencional do solo (SPC) (Thompson \& Whitney, 1998). A quantidade suplementar necessária de $\mathrm{N}$ no SPD varia com a quantidade de cobertura morta (pal ha), com a composição química do resíduo e com o período em quea pal ha é dessecada rel ativamente à semeadura da cultura subseqüente (Vaughan \& Evanylo, 1998). A cobertura do solo por resíduos vegetais dificulta, também, o contato entre o fertilizante e o solo. I sso facilita a volatilização de $\mathrm{N}$ a partir da aplicação superficial de uréia. Essa reação intensifica-se nas lavouras em que o cal cário é aplicado sobre a superfície do solo, sem incorporação (Howard \& Essington, 1998), decorrente do aumentosubstancial no pH da camada superficial do solo (Ernani et al., 2001).

A menor oxigenação do sol o noSPD é outro fator responsável pela necessidade de maiores quantidades de $\mathrm{N}$ nesse sistema relativamente ao SPC, pois envolve menor mineralização do $\mathrm{N}$ nativo presente na matéria orgânica do solo (Bayer et al., 2000). O efeito da percolação deágua, da distribuição relativa da porosidade e suas conseqüências na lixiviação de N têm sido pouco estudados no SPD.

As informações existentes sobre o desenvol vimento das plantas no SPD, em sua maioria, referem-se ao rendimento vegetal em campo, sendo específicas às condições de solo e clima existentes nos locais dos experimentos. Muitos resultados conflitantes sobre o manejo do nitrogênio no plantio direto têm sido obtidos entre diferentes experimentos, por nãoserem conhecidos, com muita profundidade, os mecanismos bási cos de como el es são influenciados pela variação nas características de solo e da planta nesse sistema. O conhecimento dessas reações, além de permitir esse entendimento, irá facilitar a recomendação consistente de tecnologias de fertilização de solo, específicas a cada situação de lavoura, que possibilitem maximizar a eficiência de uso do N.

No presente trabalho, objetivou-se quantificar a lixiviação e a imobilização de $\mathrm{N}$ no solo a partir da combinação de formas de aplicação da uréia e da palha de aveia preta, em casa de vegetação.

\section{MATERIAL E MÉTODOS}

O trabalho constou de dois experimentos, realizados em 1999, em casa de vegetação, na Universidade do estado de Santa Catarina (UDESC), em Lages (SC), com o objetivo de avaliar, respectivamente, a lixi viação ea imobilização do nitrogênio no solo. Utilizaram-se amostras com estrutura deformada de um Nitossol o Vermel ho, coletadas na camada arável (0-20 cm de profundidade) em uma área de vegetação campestre nativa, que continha $49 \mathrm{~g} \mathrm{~kg}^{-1}$ de matéria orgânica, $520 \mathrm{~g} \mathrm{~kg}^{-1}$ de argila e $\mathrm{pH}$ em água 4,8.

Nos dois experimentos, os tratamentos consistiram da combinação de três formas de aplicação dos resíduos da parte aérea de aveia preta (sem palha, pal ha na superfície do solo ou pal ha incorporada ao solo) com três formas de aplicação de nitrogênio mineral (sem uréia, uréia na superfície ou uréia incorporada), em arranjo fatorial. No experimento de lixiviação, avaliou-se também o efeito de dois níveis de pH do solo $(5,5$ e 7,0$)$ e, no de imobilização, de três épocas de semeadura do milho após a aplicação dos tratamentos, como fatores adicionais.

A palha de aveia preta foi coletada numa lavoura que se encontrava no estádio de florescimento e apresentou uma rel ação carbono/nitrogênio de 40:1. Depois de seca em estufa a $60^{\circ} \mathrm{C}$, durante três dias, a palha foi cortada em fragmentos, com aproximadamente $2 \mathrm{~cm}$ de comprimento, e aplicada na quantidade equivalente a $4,0 \mathrm{Mg} \mathrm{ha}^{-1}(3,14 \mathrm{e}$ 12,56 g de matéria seca por unidade experimental, respectivamente, no experimento de lixiviação e imobilização). O N foi aplicado na forma de uréia sólida, na dose equivalente a $200 \mathrm{~kg} \mathrm{ha}^{-1}$, no experimento delixiviação (157 mg de N por coluna), e a $100 \mathrm{~kg} \mathrm{ha}^{-1}$, no experimento de imobilização (310 mg de $\mathrm{N}$ por vaso). As quantidades de pal ha e de $\mathrm{N}$ foram calculadas, considerando a área da superfície do solo de cada unidade experimental. Nos tratamentos que receberam palha e uréia sobre a superfície do solo, aplicou-se primeiro a palha e, em seguida, ofertilizante. As quantidades deN adicionadas pela palha de aveia nos experimentos de lixiviação e imobilização foram de 31 e 126 mg, respectivamente, equival entes a 20 e $41 \%$ do $\mathrm{N}$ aplicado pela uréia em cada experimento. Nos dois experimentos, utilizou-se o delineamento completamente casual izado e três repetições por tratamento. 
No experimento de lixiviação, as unidades experimentais ( $1,58 \mathrm{~kg}$ de sol o, base seca ao ar) foram acondicionadas em colunas de PVC, sendo a lixiviação avaliada pela determinação do $\mathrm{N}$ na solução percolada. As colunas tinham $30 \mathrm{~cm}$ de altura e $10 \mathrm{~cm}$ de diâmetro, ea base das mesmas foi vedada com uma tampa, também de PVC, que continha um orifício central com $3 \mathrm{~mm}$ de diâmetro, ao qual se conectou um tubo plástico, de mesmo diâmetro, para permitir a saída gravitacional da solução percolada.

Para promover a percolação líquida, $300 \mathrm{~mL}$ de água destilada foram adicionados por semana, numa única vez, durante dez semanas. A água foi col ocada sobre a parte superior de cada coluna, e o volume semanal foi equivalente a aproximadamente $40 \%$ da porosidadetotal de cada coluna. No dia seguinte à adição de água, coletou-se a solução percolada, e nel a foram determinados o vol ume e a concentração de $\mathrm{N}$ mineral (amônio + nitrato), bem como foi cal culada a quantidade de $\mathrm{N}$ lixiviado. O N mineral foi determinado por destilação, em aparelho semimicro-kjeldahl, conforme método descrito por Tedesco et al. (1995).

No experimento de imobilização, as unidades experimentais (5,0 kg de solo, base seca ao ar) foram acondicionadas em vasos plásticos com $20 \mathrm{~cm}$ de diâmetro e capacidade para $6,0 \mathrm{~L}$, e nelas cultivaram-se plantas de milho, durante 30 dias, em casa de vegetação. A imobilização de $\mathrm{N}$ foi avaliada indiretamente, por meio do acúmulo de $\mathrm{N}$ na parte aérea das plantas, semeadas em diferentes épocas (0, 30 ou 60 dias) após a aplicação dos tratamentos. Para isso, utilizaram-se três conjuntos de unidades experimentais, com os mesmos tratamentos, todos aplicados no dia da primeira semeadura. O solo, previamente corrigido com calcário dolomítico até atingir pH 5,5 em água, recebeu fósforo e potássio, junto com os tratamentos, nas doses de 150 e $100 \mathrm{mg} \mathrm{kg}^{-1}$, respectivamente. Utilizaram-se seis plantas por vaso do híbrido superprecoce Cargill 909. Água destilada foi adicionada diariamenteaos vasos, sendo o volume necessário determinado por pesagem.

Analisaram-se as matérias secas da parte aérea e de raízes, após secagem em estufa a $60^{\circ} \mathrm{C}$, e a concentração e o acúmulo de $\mathrm{N}$ na parte aérea. O N foi determinado pel o método descrito por Tedesco et al. (1985). Nos tratamentos em que a pal ha de aveia foi aplicada sobre a superfície do solo, avaliou-se a quantidade de palha remanescente, ao término de cada cultivo, por meio de pesagem, e calculou-se a percentagem de decomposição da pal ha relativamente ao total aplicado.

Os dados foram analisados estatisticamente pela análise devariância. Quando atingida significância estatística, as médias foram comparadas pel o teste de Duncan a $5 \%$.

\section{RESULTADOS E DISCUSSÃO}

\section{Experimento de lixiviação}

A forma de aplicação da palha de aveia não interagiu com o pH do solo ou com os tratamentos de $\mathrm{N}$ no tocante à lixiviação, possivel mente porque a quantidade de $\mathrm{N}$ imobilizado foi pequena em relação às quantidades mineralizadas eadicionadas pel o fertilizante nitrogenado. Na média das formas de adição da palha, o N total lixiviado nos tratamentos sem adição de uréia foi de $67 \mathrm{mg}$ coluna-1 $\left(42,2 \mathrm{mg} \mathrm{kg}^{-1}\right)$, no $\mathrm{pH} 5,5$, e de $124 \mathrm{mg}$ coluna-1 $^{-1}$ (78,5 $\mathrm{mg} \mathrm{kg}^{-1}$ ), no pH 7,0 (Quadro 1). Essa alta lixiviação nos tratamentos sem $\mathrm{N}$ deve-se, provavel mente, ao incremento na decomposição da matéria orgânica nativa do solo (MOS), a qual é elevada nos primeiros dias após a mobilização do solo (J ackson, 2000), principalmente no pH mais alto, quando a mineralização é maior (Gianello et al., 2000).

Por serem as condições de oxigenação, umidade e temperatura favoráveis à atividade microbiana, é provável que todo o amônio mineralizado tenha sido nitrificado durante as dez semanas de duração do experimento (Aulakh et al., 2000). Rápida nitrificação também foi observada por Griffin \& Honeycutt (2000), que verificaram ter o amônio desapareci do nos primeiros 28 dias após a aplicação de estercos animais ao solo. Como o solo do presente trabalho apresenta somente cargas negativas nos valores de $\mathrm{pH}$ avaliados (Albuquerque et al., 2000), e o nitrato não é adsorvido por complexos de esfera interna, a maioria do $\mathrm{N}$ nitrificado lixiviou.

A lixiviação do $\mathrm{N}$ aplicado diminuiu com o aumento do pH do solo (Quadro 1). A lixiviação do

\section{Quadro 1. Nitrogênio total lixiviado e percentagem em relação ao aplicado após dez percolações de água destilada através de colunas preenchi- das com um Nitossolo Vermelho (1,58 $\left.\mathrm{kg} \mathrm{coluna}^{-1}\right)$, considerando o pH do solo e o método de aplicação de uréia (158 $\mathrm{mg}^{-1}$ coluna $\left.^{-1} \mathrm{de} \mathrm{N}\right)$ e da palha de aveia $\left(4,0 \mathrm{Mg} \mathrm{ha}^{-1}\right)$}

\begin{tabular}{|c|c|c|c|}
\hline $\begin{array}{l}\text { pH do } \\
\text { solo }\end{array}$ & Sem N & $\mathbf{N}$ incorporado & N na superfície \\
\hline & & mg $N$ coluna-1 & \\
\hline 5,5 & $67,1 \mathrm{C} \mathrm{b}$ & $177,2 \mathrm{~A}$ a $(70 \%)^{(1)}$ & 117,2 B b (32 \%) \\
\hline 7,0 & $123,9 \mathrm{C} \mathrm{a}$ & 190,5 A a (42 \%) & 162,6 B a (25 \%) \\
\hline
\end{tabular}

Médias seguidas pela mesma letra, maiúsculas na linha e minúsculas na coluna, não diferem significativamente pelo teste de Duncan a $5 \%$.

(1) Percentagem de $\mathrm{N}$ lixiviado em relação ao $\mathrm{N}$ mineral aplicado, após subtrair, em cada nível de acidez, o N lixiviado no tratamento que não recebeu $\mathrm{N}$ mineral. 
$\mathrm{N}$ oriundo do fertilizante mineral, obtido pela diferença entre o $\mathrm{N}$ total lixiviado em cada tratamento e o $\mathrm{N}$ lixiviado no tratamento em que se aplicou uréia, em cada nível deacidez, variou de $25 \%$, no tratamento com uréia na superfície e pH 7,0, até $70 \%$ naquele com uréia incorporada e pH 5,5. A menor lixiviação do $\mathrm{N}$ oriundo da uréia nos maiores valores de $\mathrm{pH}$ se deve, provavelmente, ao maior número de cargas el étricas líquidas negativas nesse tratamento (Bigel ow et al ., 2001), que, ao adsorverem mais amônio, retarda a nitrificação.

A lixiviação do $\mathrm{N}$ aplicado variou com a forma de aplicação do fertilizante nitrogenado. Ela foi maior quando a uréia foi incorporada ao sol o do que quando aplicada sobrea superfície(Quadro 1), provavelmente em virtude da maior volatilização de amônia (Howard \& E ssington, 1998; Palma et al., 1998), e, ou, do retardamento da nitrificação nos tratamentos com uréia na superfície, em decorrência do menor contato do fertilizante com o solo. Perdas de N por volatilização de amônia de até 54 \% em relação ao aplicado foram observadas após a aplicação de uréia sobre o solo no sistema plantio direto, em Minas Gerais, as quais diminuíram para $5 \%$ quando o fertilizante foi incorporado (Lara Cabezas et al., 2000). Valores bem mais baixos, no entanto, foram obtidos por Palma et al. (1998), ao aplicarem uréia sobre a superfície de um sol o argentino, onde apenas 11,5 e $8,6 \%$ do $\mathrm{N}$ volatilizaram nos sistemas de preparo direto e convencional, respectivamente.

Os dados obtidos no presente trabal ho mostram que parte do $\mathrm{N}$ mineral adicionado ao solo não lixiviou, mesmo após dez percolações sucessivas com água destilada.

O N total lixiviado, que inclui o $\mathrm{N}$ mineralizado da matéria orgânica e oN adicionado pel o fertilizante, nem sempre teve o mesmo comportamento que o $\mathrm{N}$ oriundo do fertilizante (Quadro 1). Em relação à forma de aplicação da uréia, el es foram semel hantes, ou seja, a lixiviação foi maior nos tratamentos com uréia incorporada do que naqueles com uréia aplicada sobre a superfície do solo. Em relação ao $\mathrm{pH}$, no entanto, o $\mathrm{N}$ total lixiviado variou com a forma de aplicação da uréia: quando ela foi incorporada, o $\mathrm{pH}$ não influenciou a lixiviação, mas quando ela foi aplicada sobre a superfície, a lixiviação total de N foi maior no $\mathrm{pH} 7,0$ do que no $\mathrm{pH}$ 5,5.

A época em que ocorreu a máxima lixiviação de $\mathrm{N}$ foi influenciada pelo $\mathrm{pH}$ epelo método de apl icação da uréia ao solo (Figura 1). Quando a uréia foi incorporada ao solo, a quantidade de $\mathrm{N}$ lixiviado nos tratamentos com pH 5,5 aumentou até à quinta percolação de água e depois decresceu; nos tratamentos com pH 7,0, a lixiviação aumentou gradativamente até à oitava percolação. Quando a uréia foi aplicada sobre a superfície do solo, a quantidade máxima de $\mathrm{N}$ lixiviado não foi influenciada pelo $\mathrm{pH}$ do solo, e ocorreu na oitava percolação (Figura 1).

O retardamento da lixiviação, após a adição de fertilizantes ao solo, é extremamente desejável, pois permite um maior período de absorção pelas plantas, aumentando, com isso, a utilização do nutriente. A movimentação de nitratos para camadas profundas do solo é indesejável, pois, além de diminuir o uso do $\mathrm{N}$ pelas plantas, pode contaminar as águas subterrâneas (Aulakh et al., 2000; Ottman \& Pope, 2000). A diminuição da dose de $\mathrm{N}$ a ser aplicada, ou o seu parcelamento (Errebhi et al., 1998; Basso \& Ceretta, 2000), assim como o uso de plantas com sistema radicular profundo (Menezes et al., 1997; Aulakh et al., 2000), seriam algumas alternativas para minimizar as perdas de N por lixiviação.

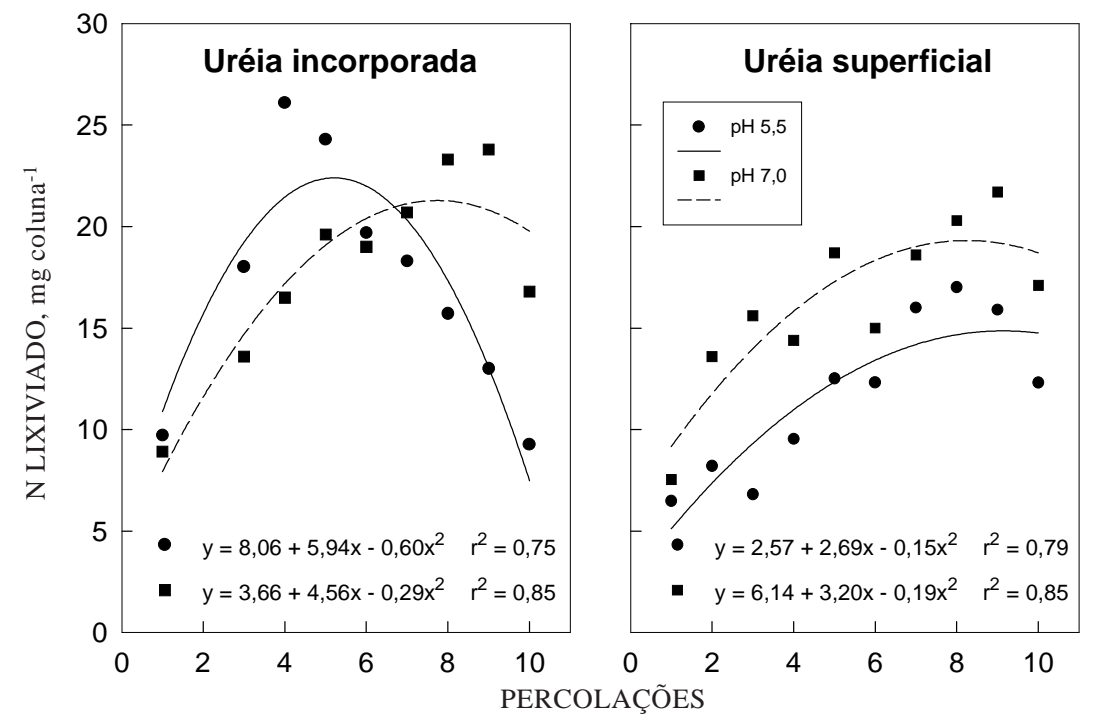

Figura 1. Nitrogênio total lixiviado em cada uma das dez percolações de água destilada, considerando o pH e o método de aplicação da uréia num Nitossolo Vermelho. 


\section{Experimento de imobilização}

Nesse experimento, não houve interação de nenhum dos três fatores avaliados (época de semeadura e formas de aplicação da palha ou da uréia) para qualquer determinação. Sendo assim, serão discutidos somente os efeitos principais.

O intervalo de tempo entre a adição dos tratamentos (palha e N) e a semeadura afetou a absorção de nitrogênio e o rendimento de matéria seca de milho. A maior absorção de nitrogênio e as maiores produções de matéria seca da parte aérea ocorreram quando a semeadura do milho foi realizada 30 e 60 dias após a aplicação de pal ha e N (Quadro 2). Os menores val ores para esses dois atributos foram obtidos no mil ho semeado no dia da aplicação dos tratamentos, provavel mente por causa da maior imobilização líquida de $\mathrm{N}$ nos primeiros trinta dias após a aplicação da palha, conforme demonstrado por Sampaio \& Salcedo (1993), para a pal ha de mil ho. O período de imobilização de $\mathrm{N}$ após a aplicação de resíduos orgânicos ao solo é, normal mente, de al guns meses (Trinssoutrot et al., 2000), porém é mais intenso nos primeiros dias.

Griffin \& Honeycutt (2000) observaram imobilização de $\mathrm{N}$ de até $30 \%$ nas duas primeiras horas após a aplicação de resíduos animais ao solo; Sampaio \& Salcedo (1993) verificaram que a adição de $3,0 \mathrm{~g} \mathrm{~kg}^{-1}$ de pal ha de milho imobilizou até $50 \%$ dos $36 \mathrm{mg}$ de $\mathrm{N}$ aplicados pela uréia, em experimentos com vasos. Trinssoutrot et al. (2000) aplicaram 47 tipos de resíduos vegetais ao solo e verificaram que somente dois deles, ambos com relação C/N menor que24, ocasionaram mineralização positiva de $\mathrm{N}$ no período estudado de 168 dias.

Apesar de ter havido resposta à aplicação de N, a forma de aplicação da uréia não influiu na absorção de $\mathrm{N}$ e no rendimento de massa seca. Verifica-se que, quando as doses de $\mathrm{N}$ adicionadas são maiores que a necessidade das culturas, orendimento vegetal não tem sido afetado pelo método de aplicação ou pela presença ou não de palha (Sims et al., 1998) porque as perdas de $\mathrm{N}$, nesse caso, são inferiores ao excesso disponível.

Essa situação ocorreu no presente trabal ho, uma vez que foram adicionados $310 \mathrm{mg}$ vaso-1 $^{-1}$ de N, eapós subtrair oN acumulado pelas plantas no tratamento onde não se aplicou N mineral, menos de $30 \%$ do N aplicado foi acumulado na parte aérea das plantas nos demais tratamentos (Quadro 2). Sabendo que as raízes acumulam menor quantidade de $\mathrm{N}$ que a parte aérea e que o rendimento de matéria seca do sistema radicular foi menor que a fitomassa aérea (Quadro 2), menos de $50 \%$ do $\mathrm{N}$ aplicado foi absorvido pelas plantas.

A adição depal ha teve efeitos positivos enegativos na absorção de $\mathrm{N}$ e no rendimento de massa seca de milho, dependendo do método de aplicação. A palha mantida na superfície do sol o estimul ou a absorção
Quadro 2. Produção de massa seca da parte aérea (MSPA) e das raízes (MSR) e conteúdo de nitrogênio na parte aérea de milho, influenciados pela época de semeadura e pelas formas de aplicação da uréia e dos resíduos de aveia num Nitossolo Vermelho

\begin{tabular}{|c|c|c|c|}
\hline É poca de semeadura(1) & MSPA & MSR & $\mathbf{N}$ absorvido \\
\hline & \multicolumn{2}{|c|}{$\mathrm{g}_{\text {vaso }}{ }^{-1}$} & mg vaso-1 \\
\hline $\begin{array}{r}0 \\
30 \\
60\end{array}$ & $\begin{array}{l}4,27 \mathrm{~b} \\
5,46 \mathrm{a} \\
5,63 \mathrm{a}\end{array}$ & $\begin{array}{l}3,30 \mathrm{~b} \\
4,86 \mathrm{a} \\
2,91 \mathrm{c}\end{array}$ & $\begin{array}{l}119 b^{(2)} \\
150 a \\
161 a\end{array}$ \\
\hline \multicolumn{4}{|l|}{ Manejo do N } \\
\hline $\begin{array}{l}\text { Sem } \mathrm{N} \\
\mathrm{N} \text { na superfície } \\
\mathrm{N} \text { incorporado }\end{array}$ & $\begin{array}{l}4,23 \mathrm{~b} \\
5,75 \mathrm{a} \\
5,39 \mathrm{a}\end{array}$ & $\begin{array}{l}3,57 a \\
3,93 a \\
3,58 a\end{array}$ & $\begin{array}{r}94 \mathrm{~b} \\
174 \mathrm{a} \\
163 \mathrm{a}\end{array}$ \\
\hline \multicolumn{4}{|l|}{ Manejo da palha } \\
\hline $\begin{array}{l}\text { Sem palha } \\
\text { Palha na superfície } \\
\text { Palha incorporada }\end{array}$ & $\begin{array}{l}4,82 \mathrm{~b} \\
6,42 \mathrm{a} \\
4,12 \mathrm{c}\end{array}$ & $\begin{array}{l}3,60 \mathrm{~b} \\
4,10 \mathrm{a} \\
3,38 \mathrm{~b}\end{array}$ & $\begin{array}{l}138 b \\
178 a \\
115 c\end{array}$ \\
\hline
\end{tabular}

$\overline{{ }^{(1)} \text { A semeadura foi realizada no dia da aplicação dos tratamen- }}$ tos, 30 e 60 dias após, respectivamente. (2) Médias seguidas por mesma letra, na coluna, para cada efeito simples de tratamento, não diferem significativamente pelo teste de Duncan a $5 \%$.

de nitrogênio pelas plantas demilho, o que se refletiu no aumento da produção de massa seca da parte aérea (Quadro 2). Esse efeito benéfico da pal ha possivel mente foi ocasionado pela manutenção de maiores teores de umidade no solo (Vaughan \& E vanylo, 1998), cuja magnitude superou os possíveis efeitos negativos que a cobertura da superfície do solo poderia ter sobre a imobilização de $\mathrm{N}$.

Mesmo em casa de vegetação, onde o solo é umedecido diariamente, ocorrem períodos de reduzida umidade do solo. A manutenção da pal ha diminuiu, nesse caso, as perdas de água por evaporação e contribuiu para o crescimento do mi lho. O maior rendimento de massa seca de raízes no tratamento com pal ha na superfícierelativamenteaos com pal ha incorporada (Quadro 2) reforça a hipótese de que a palha superficial contribuiu para a manutenção de umidade no solo. A incorporação da palha, por outro lado, afetou a absorção de N, limitando, por conseguinte, a produção de biomassa vegetal da parte aérea, possivelmente pelo incremento na imobilização de N (Vaughan \& Evanylo, 1998). Quando a palha é incorporada ao solo, espera-se maior imobilização de $\mathrm{N}$ do que quando ela é deixada sobre a superfície porque a incorporação aumenta o contato com os microrganismos.

A decomposição dos restos culturais de aveia aplicados sobrea superfície do sol o foi rápida e variou com a adi ção do fertilizante nitrogenado. Sem adi ção de N, a decomposi ção da pal ha variou de $16,5 \%$, aos 
30 dias, até $37,8 \%$, aos 90 dias. Quando se aplicou $\mathrm{N}$ ao solo, os valores foram maiores, pois aproximadamente $50 \%$ da palha havia sido decomposta aos 30 dias, independentemente do modo de aplicação da uréia. No sol o ondea uréia foi aplicada na superfície, a decomposição da palha estabilizou-se aos 30 dias, porém, quando ela foi incor porada, a decomposição dos resíduos continuou aumentando até à última época avaliada (90 dias), atingindo valores de 68,7\% (Quadro 3). Esses valores são altos e mostram porque a imobilização de $\mathrm{N}$ é maior nas primeiras semanas após a dessecação das plantas utilizadas como cobertura de solo no sistema de plantio direto. Bortoluzzi $\&$ Eltz (2000) verificaram, em campo, que aproximadamente 40 e $50 \%$ da palha de aveia picada foi decomposta, respectivamente, aos 30 e 53 dias de sua aplicação numa lavoura de soja.

\section{Quadro 3. Percentagem de decomposição da palha de aveia em diferentes épocas após a aplicação na superfície de um Nitossolo Vermelho, considerando a aplicação de uréia}

\begin{tabular}{cccc}
\hline $\begin{array}{c}\text { Dias } \\
\text { após } \\
\text { adição }\end{array}$ & Sem N & N incorporado & N na superfície \\
\hline & & & \\
30 & $16,5 \mathrm{Bb}$ & $47,0 \mathrm{Ab}$ & $48,4 \mathrm{Aa}$ \\
60 & $21,6 \mathrm{Bb}$ & $47,9 \mathrm{Ab}$ & $52,6 \mathrm{Aa}$ \\
90 & $37,8 \mathrm{Ca}$ & $68,7 \mathrm{Aa}$ & $51,8 \mathrm{Ba}$ \\
\cline { 2 - 3 } & & &
\end{tabular}

* Médias sucedidas pela mesma letra, maiúsculas na linha e minúsculas na coluna, não diferem significativamente pelo teste de Duncan a $5 \%$.

\section{CONCLUSÕES}

1. A lixiviação do $\mathrm{N}$ aplicado não é influenciada pela forma de aplicação da palha de aveia ao solo, mas é maior nos tratamentos com uréia incorporada do que com uréia na superfície do sol o, enos menores valores de $\mathrm{pH}$. A lixiviação total máxima acontece mais tarde nos menores valores de $\mathrm{pH}$ ou quando o fertilizante nitrogenado é apli cado sobre a superfície do solo, o que deve favorecer a absorção do $\mathrm{N}$ pelas plantas.

2. O atraso na semeadura do milho, em relaçãoà adição dos restos culturais de aveia, aumenta a absorção de nitrogênio e produção de fitomassa, possivelmente, em virtude da diminuição na imobilização de $\mathrm{N}$.

3. A manutenção dos restos culturais de aveia sobre a superfície do solo aumenta a absorção de nitrogênio e a produção de massa seca do milho, independentemente do manejo da adubação nitrogenada.

\section{LITERATURA CITADA}

ALBUQUERQUE,J .A.; BAYER, C.; ERNANI, P.R. \& FONTANA, E.C. Propriedades físicas e el etroquímicas de um $L$ atossolo afetadas pela calagem. R. Bras. Ci. Solo, 24:295-300, 2000.

AMADO, T.J.C. \& MIELNICZUK, J. Estimativa da adubação nitrogenada para o milho em sistemas de manejo e culturas de cobertura do solo. R. Bras. Ci. Solo, 24:553-560, 2000.

AULAKH, M.S.; KHERA, T.S.; DORAN, J.W.; SINGH, K. \& SINGH, B. Yields and nitrogen dynamics in a rice-wheat system using green manure and inorganic fertilizer. Soil Sci. Soc. Am. J ., 64:1867-1876, 2000.

BASSO, C.J . \& CERETTA, C.A. Manejo do nitrogênio no milho em sucessão a plantas de cobertura de solo, sob plantio direto. R. Bras. Ci. Solo, 24:905-915, 2000.

BAYER, C.; MIELNICZUK, J. \& MARTIN-NETO, L. Efeito de sistemas de preparo e de cultura na dinâmica da matéria orgânica e na mitigação das emissões de $\mathrm{CO}_{2}$. R. Bras. Ci. Solo, 24:553-560, 2000.

BIGELOW, C.A.; BOWMAN, D.C. \& CASSEL, D.K. Nitrogen leaching in sand-based rootzones amended with inorganic soil amendments and sphagnum peat. J. Am. Soc. Hort. Sci., 126:151-156, 2001.

BORTOLUZZI, E.C. \& ELTZ, F.L.F. Efeito do manejo mecânico da palhada de aveia preta sobre a cobertura, temperatura, teor deágua no sol o eemergência da soja em sistema plantio direto. R. Bras. Ci. Solo, 24:449-457, 2000.

COMISSÃO DE FERTILIDADE DO SOLO - CFS/RS-SC. Recomendações de adubação e de calagem para os estados do Rio Grande do Sul e de Santa Catarina. 3.ed. Passo Fundo, SBCS-Núcleo Regional Sul, 1995. 224p.

ERNANI, P.R.; NASCIMENTO, J.A.L. \& FREITAS, E.G. Aumento do rendimento de grãos e de massa verde de milho para silagem pela aplicação de nitrogênio. Agropec. Gaúcha, 2:201-205, 1997.

ERNANI, P.R.; RIBEIRO, M.F.S. \& BAYER, C. Modificações químicas em solos ácidos ocasionadas pelo método de aplicação de corretivos da acidez e de gesso agrícola. Sci. Agríc., 58:825-831, 2001.

ERREEBHI, M.; ROSEN, C.J .; GUPTA, S.C. \& BIRONG, D.E. Potato yield response and nitrate leaching as influenced by nitrogen management. Agron. J., 90:10-15, 1998.

GIANELLO, C.; CAMARGO, F.A.O.; REICHMANN, E. \& TEDESCO, M.J . Avaliação da disponibilidade do nitrogênio do solo estimada por métodos químicos. R. Bras. Ci. Solo, 24:93-101, 2000.

GRIFFIN,T.S. \& HONEYCUTT, C.W. Using growing degree days do predict nitrogen availability from livestock manures. Soil Sci. Soc. Am. J ., 64:1876-1882, 2000.

HOWARD, D.D. \& ESSINGTON, M.E. Effects of surface-applied limestone on the efficiency of urea-containing nitrogen sources for no-till corn. Agron. J., 90:523-528, 1998.

JACKSON, L.E. Fates and losses of nitrogen from a nitrogen15-labeled cover crop in an intensively managed vegetable system. Soil Sci. Soc. Am. J ., 64:1404-1412, 2000. 
LARA CABEZAS, W.A.R.;TRIVELIN, P.C.O.; KONDÖRFER, G.H. \& PEREIRA, S. Balanço da adubação nitrogenada sólida e fluída de cobertura na cultura do milho, em sistema plantio direto no Triângulo Mineiro. R. Bras. Ci. Solo, 24:363-376, 2000.

MENEZES, R.S.C.; GASCHO, G.J .; HANNA, W.W.; CABRERA, M.L. \& HOOK, J.E. Subsoil nitrate uptake by grain pearl millet. Agron. J ., 89:189-194, 1997.

OOTMAN, M.J. \& POPE, N.V. Nitrogen fertilizer movement in the soils as influenced by nitrogen rate and timing in irrigated wheat. Soil Sci. Soc. Am. J., 64:1883-1892, 2000.

PALMA, R.M.; SAUBIDET, M.I.; RIMOLO, M. \& UTSUMI, J. Nitrogen losses by volatilization in a corn crop with two tillage systems in the Argentine Pampa. Comm. Soil Sci. Plant Anal., 29:2865-2879, 1998.

SAMPAI O, E.V.S.B. \& SALCEDO, I.H. Mineralização e absorção por milheto do nitrogênio do solo, da pal ha de milho- $\left({ }^{15} \mathrm{~N}\right)$ e da uréia-(15N). R. Bras. Ci. Solo, 17:423-429,1993.
SIMS, A.L.; SCHEPERS, J.S.; OLSON, R.A. \& POWER, J.F. Irrigated corn yield and nitrogen accumulation response in a comparison of no-till and conventional till: tillage and surface-residue variables. Agron. J ., 90:630-637, 1998.

TEDESCO, M.J.; VOLKSVEISS, S.J . \& BOHEN, H. Análise de solo, plantas e outros materiais. PortoAlegre, Universidade Federal do Rio Grande do Sul, 1995. 188p. (Boletim Técnico, 5)

THOMPSON, C.A. \& WHITNEY, D.A. Long-term tillage and nitrogen fertilization in a west central great plains wheatsorghum-fallow rotation. J. Prod. Agric., 11:353-359, 1998.

TRINSOUTROT, I.; RECOUS, S.; BENTZ, B.; LINÈRES, M.; CHÈNEBY, D. \& NICOLARDOT, B. Biochemical quality of crop residues and carbon and nitrogen mineralization kinetics under nonlimiting nitrogen conditions. Soil Sci. Soc. Am. J ., 64:918-926, 2000.

VAUGHAN, J.D. \& EVANYLO, G.K. Corn response to cover crop species, spring desiccation time, and residue management. Agron. J., 90:536-544, 1998. 